\title{
ESL Students' Perceptions of the use of Higher Order Thinking Skills in English Language Writing
}

\author{
Malini Ganapathy (Corresponding author) \\ English Language Studies Section, School of Languages, Literacies and Translation Universiti Sains Malaysia, 11800 Penang, Malaysia \\ E-mail: malinik@usm.my \\ Sarjit Kaur \\ English Language Studies Section, School of Humanities, Universiti Sains Malaysia \\ 11800 Penang, Malaysia \\ E-mail: sarjit@usm.my
}

Doi:10.7575/aiac.alls.v.5n.5p.80

Received: 20/06/2014

URL: http://dx.doi.org/10.7575/aiac.alls.v.5n.5p.80

Accepted: 18/08/2014

\begin{abstract}
The transformation of the education curriculum in the Malaysia Education Development Plan (PPPM) 2013-2025 focuses on the Higher Order Thinking (HOT) concept which aims to produce knowledgeable students who are critical and creative in their thinking and can compete at the international level. HOT skills encourage students to apply, analyse, evaluate and think creatively in and outside the classroom. The purpose of this exploratory study was to investigate the impact of using HOT skills in a secondary ESL writing classroom. A total of 120 Form Two ESL students from three intact classes participated in this study. The students experienced project and group-based work both independently and collaboratively in groups during their writing lessons. The findings from the focus group interviews revealed the following student perceptions: felt engaged in active learning, experienced learner autonomy, developed their writing, researching and personal skills. The implications of this study suggest that using HOT skills in ESL writing lessons facilitate students' writing ability and interest and it is recommended that HOT skills be explicitly infused in the teaching and learning of writing activities in ESL classrooms.
\end{abstract}

Keywords: ESL students, higher-order thinking skills, critical thinking, writing, learner autonomy.

\section{Introduction}

The twin forces of globalisation and internationalisation have put a critical demand on the education system in Malaysia to transform dynamically in measuring up to the global needs of the 21 st century and achieving the advanced nation status vision by 2020. One of the key challenges in this perspective is to prepare students with real life skills for tomorrow's knowledge based economy that will enable them to be relevant individuals who are capable of creativity and innovative skills to be able to compete in the global labour market. Hence, the National Education Blueprint (20132025) is grounded based on high-performing systems which promote a transformation of the Malaysian education system in line with the vision of Malaysia's National Philosophy in achieving world class status. The objectives of the blueprint advocate a set of refined articulation of the specific skills and attributes which include cognitive skills, creative thinking, innovative thinking and reasoning.

\section{Review of literature}

The conception of "world-class skills are assumed to be a route to economic prosperity, reduced income inequalities and social cohesion. Such policy prescriptions rest on the idea of a knowledge economy where innovative ideas and technical expertise hold the key to the new global competitive challenge" (Brown et al., 2012:4). Malaysian students who qualify for tertiary education and graduate from the system are generally perceived as 'unfit' for employability as they are deemed lacking in quality, especially in the area of thinking skills and soft skills (Morshidi Sirat et al., 2008).

Paramjit et al. (2014:319) provides some of the reasons behind the unemployability of Malaysian graduates:

“ (1) the requirements of the knowledge based new economy and continuing impact of globalisation and new information technologies; (2) the exponential pace of change; (3) the consequent pressures of lifelong learning; (4) the need for individuals to maintain employability; (5) changes in the workplace; (6) requirement to foster enterprise skills and innovation culture in some countries"

The Ministry of Education has taken these aspects into consideration and seeks to address issues at the grassroots where students' thinking skills are concerned. The elements of the Malaysia Education Blueprint (2013-2025) in relation to Higher Order Thinking (HOT hereafter) skills are currently underway in the state of implementation. There are efforts 
to integrate higher order thinking skills in the questioning format for the national examinations and school-based assessments. The aim is to specifically ensure that by $2016,40 \%$ of questions in the Upper Primary National Assessment (UPSR) and 50\% in the Malaysian Education Certificate (SPM) comprise higher order thinking questions. This will signal a paradigm shift in teachers' traditional role in outlining the topics and questions based on past year series and later drilling for content recall. Instead, students will be familiarised with various classroom practices that will promote their HOT skills capacity to think critically, creatively and innovatively in diverse settings.

The Integrated Curriculum for Secondary Schools (ICSS, 1989) stresses on thinking skills where teachers play an important role in fulfilling the learning outcomes in the classroom by designing pedagogical activities that stimulate and encourage students to develop their thinking skills. The "contents of the curriculum promote the development of thinking abilities to enable students to analyse, synthesise, explain, draw conclusions, and produce ideas that are both constructive and useful" (Curriculum Development Center, 1989:6). The concept of HOT skills has been devised in the education system but it has not been fully implemented in classroom teachings or executed holistically. Hillocks (1986) argues that only deliberate attempts by teachers to provide high level of student autonomy and interaction seem to have an effect on students' thinking abilities.

It has also been suggested that teachers lack pedagogical knowledge in having the expertise to innovate their practices by integrating HOT skills in their lessons which does not concur with the HOT questions posed in their examinations and assessments. This will result in students' inability to answer the questions in the exams and this reflects a gap in the implementation of HOT skills. Students "should be assisted to acquire HOTS; either through the conventional teaching and learning environment or in a self- instructional, individualised manual" (Yee et al., 2012:202). There is scant research which has attempted to investigate how teachers construct pedagogical content knowledge to teach HOT skills. In fact, no studies have been carried out to investigate how teachers construct the pedagogical content knowledge for teaching language skills by integrating HOT skills in Malaysian secondary ESL classrooms. In addressing this gap in research, this paper attempts to explore the impact of using HOT skills in the teaching of writing in selected ESL classrooms.

\subsection{HOT Skills in Educational Context}

The National Research Council's (1987) project which involved several American schools outlined some significant recommendations on various approaches to synthesise theories related to HOT skills. The key finding revealed that HOT skills have an enormous impact on students' positive learning outcomes. It was found that students experienced long term memory through HOT learning processes compared to knowledge that is gained through lower-order skills, particularly rote memorisation.

In this project, teachers were enouraged to teach content information by using real-world contexts and vary it according to the need of the skill. Students will be able to apply the knowledge gained and internalise the abstract conceptual implication through the exposure of various contextual settings. In principle, findings of this project highlighted that teachers are encouraged to teach content in approaches that advocate the following learning skills: build background knowledge, classify things into categories, arrange items along some dimension, make hypotheses, draw inferences, analyse things into their components, solve problems and encourage students to think about the thinking strategies they are using.

The implication draws on the students' motivation where teachers play a role in ensuring that their pedagogical practices integrate the subject matter and HOT skills that will facilitate students' engagement in the lessons and spur their interest at the same time. Taking this factor into consideration, teachers' creativity can be reinforced by ensuring that students engage in real-world problems to cultivate their critical thinking skills and allow students to have a handson in debates which will enable them to participate in thinking about a range of societal issues. Teachers should ensure that assessments and classroom exercises should take into account new and realistic contexts and problems to promote HOT skills (apply knowledge) among students.

\subsection{Hot Strategies In Pedagogical Practices}

Frangenheim's model (2006) grounded on Bloom's taxonomy promotes strategies for pedagogical practices by integrating HOT skills which has the Thinking Skills Framework (TSF hereafter) for students (Table 1) and is complemented with the Teacher's TSF (Table 2). This model helps teachers in understanding the importance of using HOT skills and empowers teachers with creative and innovative strategies in their pedagogical practices. Students become engaged in their learning through the TSF and they are able to practise HOT skills effectively through various activities. Results from various studies contend that students' interest and engagement in the classroom impacts on positive learning outcomes which even motivates them to pursue challenging tasks in the classroom environment (Ames, 1992; Kaplan et al., 2002). 


\begin{tabular}{l|lllll}
\hline \multicolumn{2}{c}{ Table 1.Frangenheim's (2006) Thinking Skills Framework. } \\
\hline
\end{tabular}

This study adopted Frangenheim's (2006) model. In this model, the students' TSF advocates engaging and individualised lessons where it paves the way for students to take ownership of their learning. In this TSF (Table 1), students will be able to understand the intended learning outcomes that the teacher designs through various questions and activities which educates students in the six cognitive levels of Bloom's taxonomy. When students learn about these levels, they are also exposed to the appropriate thinking tools for each of the six levels of thinking. Frangenheim's HOT model (2006) encourages 21 st century skills of critical and creative thinking skills to be acquired through questioning at the appropriate level and scaffolding of tasks by incorporating a range of collaborative and co-operative strategies. The learning outcomes are achieved through a combination of strong content knowledge and the effects on student engagement can be dramatic.

In this model (Table 1), the first component, the Foundation Thinking Skills, consists of the skills Remember (Encyclopedia), Understand (Dictionary) and Apply ("How To' Manual). In the 'Remember Thinking Skill' component, teachers will explain to the students that they will assume the role of an Encyclopedia where they are expected to teach facts, data and information. Then they explain to the students that they will employ the skills of 
defining, listing, naming, labelling, stating, remembering and that they will use these same or similar verbs to assess students' ability to remember certain information.

When the 'Understand' skill is explored by the teacher, the teacher's role is likened to a Dictionary where definition of words, concepts and explanation of 'cause-effect' and 'reasons for' are provided by the teacher. Students are explicitly informed that they have to understand when the teacher employs the skills of explaining, summarising, interpreting, outlining and that the same or similar verbs will be used to assess students understanding of certain words, concepts, events, 'cause-effect' and 'reasons for'.

The next level facilitates students' ability to apply learnt information or skills appropriately and students are informed of this and that the teacher has to act like a 'How to Manual' in terms of showing them the application strategies in context. Students will be informed that the teacher will promote activities that relate to the skills of calculating, demonstrating, drawing, writing, solving, throwing, singing, playing an instrument and that the same or similar verbs will be used for students' assessment in order to prove that they can apply this information in relevant contexts.

The consequent section relates to HOT skills of Analyse (Sorting Tray), Evaluate (A Judge) and Design (Thomas Edison). Frangenheim's (2006) concept facilitates scaffolding where students move on to HOT skills after mastering the skills at the Foundation Skills' level. Students will be informed that the teacher can be metaphorically conceptualised as a 'Sorting Tray' to break up particular issues, events or problems into many possible components to create pathways for students to put on their thinking caps to criticially analyse information or proposals. Teachers' pedagogical practices will be learnt by students and this entails the skills of comparing, contrasting, examining, debating, investigating, exploring and in fact conducting deeper research into any topic. Students will also be informed about the use of these same or similar verbs to assess their concrete thinking ability on a topic.

The consequent stage combined with the ability to analyse, promotes 'critical thinking'. The students understand that the teacher acts like a 'Judge' at this level to evaluate the information or proposal provided by the students. Students will realise that teachers will employ the skills of deciding, ranking, selecting, justifying, choosing and recommending based on the work they have produced. The same or similar verbs will be used to assess students' work to prove that they are able to make appropriate judgments.

The final level establishes the act of the teacher being perceived as Thomas Edison who is supposed to know about the subject matter, analyse it, judge and design creative and innovative ideas. Students will be informed that they are to cultivate their creativity and teachers will implement the skills of designing, modifying, proposing, improving, embellishing and that the same or similar verbs will be administered in order to assess students' creativity.

The properties of the HOT model propogates that the teacher is responsible in preparing materials for the three foundation levels of Remember, Understand and Apply. Teachers are recommended to ensure that lessons encapsulate both the Foundation and HOT levels in order to impact students'learning outcomes. Students' creativity and innovative skills are encouraged when they are able to use their cognitive domains which will lead to more balanced learning outcomes where students will be challenged in their learning environments, leading to ownership and motivation. The elements in this TSF model systematically allows teachers to ask students to discuss, investigate, debate, explore, examine (Analyze) and then decide, select, choose, rank, recommend, defend (Evaluate) and later improve, modify, create, embellish, formulate, plan (Design). Finally, the end product proves that students will be able to use the TSF to manipulate the foundation material to generate their own ideas, opinions, inventions or designs. At present, there is scant research on using Frangenheim's (2006) TSF model in various educational contexts in Malaysia. Following this, the researchers perceive this model as vital in terms of complying to the requirements of the Malaysian Education Blueprint (2013-2025) and examining its impact in an ESL writing classroom. This study employs Frangenheim's (2006) TSF model to explore the impact of using HOT skills in the teaching of writing.

\section{Methodology}

\subsection{Research Questions}

The study was guided by the following research questions:

RQ 1: What is the impact of Higher Order Thinking skills on ESL students' learning of writing?

RQ 2: What are ESL students' perceptions of learning writing using Higher Order Thinking Skills?

\subsection{Research Design}

This research employed a case study design in view of the exploratory nature of this study to analyse students' perceptions of learning writing using HOT skills. It aimed to examine the effectivenes of HOT in students' learning of writing. Following this, the study used action research as the researchers wanted to provide a detailed and accurate observation as to the manner in which HOT skills can be used in a secondary ESL writing classroom. The action research carried out in operationalising this study's HOT framework was contextualised in relation to similar situations in which the practices can be carried out. The findings of this case study has the potential of providing wider implications, especially with the current implementation of the school-based assessment system and this will be relevant for a range of stakeholders such as ESL teachers and students in schools, trainers at Teacher's Training Colleges, curriculum designers and officers in the Ministry of Education responsible for organising professional development courses for secondary school teachers in Malaysia. 


\subsection{Research Sample}

A sample of 1 ESL teacher and 120 students (3 intact Form Two class) were selected. The same ESL teacher taught the 3 intact Form Two classes at the selected school. The Principal had sought the cooperation of the researchers not to name the school, teacher or students, as a measure of safeguarding the privacy of the ESL teacher and students involved in this study. Hence, the school will be named as 'School A' and the location of this government school was in an urban setting in the state of Penang. The students were identified based on purposive sampling as Form Two classes were the target group that is currently experiencing the national school-based assessment system. The action research ESL teacher was selected based on the criteria that her three English classes were selected as the sample for this study.

\subsection{Research Instrument}

The main research instrument used in this study was focus group interviews. Focus group interviews allow the researcher to witness dynamic, interactive discussion about the designated topics (Cohen, Manion \& Morrison, 2011). Focus group interviews were held with 48 students who volunteered from the three intact classes (comprising 16 students from each Form Two class). The interview sessions, which were held in a classroom immediately after school hours, aimed to elicit students' perceptions concerning the impact of using HOT skills in their ESL writing classroom.

Interview sessions were held after the completion of the teaching of writing using HOTS (four weeks). An interview schedule, based on Frangenheim's (2006) HOT model, was constructed in order to enable the formulation of appropriate questions that will facilitate the collection of the required data to answer the research questions. The construction of interview questions for the ESL students was given due consideration in regards to the research questions, objectives and HOT skills' framework of this study. This procedure involved segregating themes and issues in relation to the area of study which is closely aligned to the teaching and learning of writing using HOT skills. The responses provided by the ESL students were then analysed deductively. The analysis looked into various aspects that encompassed the manner in which the students perceived the effectiveness of learning writing using the TSF.

\subsection{Procedure}

The action research ESL teacher, a graduate teacher who has 27 years of teaching experience, was guided by the researchers on understanding the teachers' and students' TSF. A total of ten training sessions (which took place over 4 weeks) were held with the ESL teacher to ensure that the elements in the TSF were comprehensively understood and all the lessons were designed collaboratively with the researchers. Lessons were aligned to ensure students had ownership and purpose according to all the six choices in the TSF cognitive domain.

During the planning stage of the training sessions, the ESL teacher was briefed on the features of incorporating HOT skills in the designing of the writing lesson plans (Table 2) which is in relation to the TSF. These included the following tasks: asking open-ended questions, expecting students to provide evidence to support their answers, asking students to write down their thinking, building on students' questions, modeling the thinking process and providing specific feedback. These features of HOT skills integrated in the writing lessons were part of the journey in ensuring that students mastered the art of writing descriptive writing and that the processes experienced by students were engaging while creativity was promoted during the various activities.

The TSF poster (Table 1) was the guideline used by the teacher to design the HOT lessons by taking into consideration Blooms' levels of Remember, Understand, Apply, Analyse, Evaluate and Design. The six elements in the TSF played an important role in ensuring HOT skills were utilised when the ESL teacher integrated the use of appropriate verbs, sentence starters and most importantly, the use of appropriate thinking tools in the writing lessons as reflected in the HOT lesson plan (Table 2).

Table 2. Lesson plan based on the topic 'Environment'

\begin{tabular}{ll}
\hline \multicolumn{1}{c}{ Task Sequence } & \multicolumn{1}{c}{ Bloom's taxonomy Level } \\
\hline $\begin{array}{l}\text { Students are given information on the } \\
\text { characteristics of descriptive writing. }\end{array}$ & $\begin{array}{l}\text { Remember: Acting like an internet database } \\
\text { to recall teacher's information, } \\
\text { characteristics and find more information }\end{array}$ \\
$\begin{array}{l}\text { Students are posed with questions } \\
\text { (What) on the characteristics of }\end{array}$ & from the internet. Search the internet for \\
match the icon they are expected to & further information on Descriptive writing. \\
act like. & List characteristics of Descriptive writing \\
\hline
\end{tabular}

Discuss in groups and explain how deforestation has impacted on Malaysia's environment. Students are posed questions (Why) on the reasons behind deforestation and the manner in which (How) it has impacted the environment. Students related pose questions to their peers.
Understand: Acting like an expert, showing understanding of words, concepts, cause and effect and 'reasons for'! Give reasons for deforestation in Malaysia. Discuss the cause and effect. Discuss and explain how deforestation has impacted Malaysia based on cause-effect map. 
Students conduct an interview to collect data on issues related to the cause and effect of deforestation. Students compile information on deforestation. Students (Groups) dramatise (Role play) the cause and effect of deforestation (Why and How questions are in the script). Students write a Descriptive essay on Deforestation in Malaysia.
Apply: Acting to apply new skills, rules and concepts to related and new situations. Compile information through interview. Dramatise cause and effect of deforestation in Malaysia based on a script (Group work). Complete writing a Descriptive essay task.
Students investigate and identify global issues related to deforestation. Discuss similarities and differences between deforestation in Malaysia and globally in groups.
Analyse: Acting like a magnifying glass to identify the component parts of an issue, situation or object. Investigate all factors related to global deforestation. Discuss with friends around the globe (social media) in order to identify similarities and differences of deforestation in Malaysia and globally. Findings are stated on fishbone diagram.

\section{Task Sequence}

Students will assess and conclude on the extent of destruction that deforestation has caused in Malaysia and globally. as judge-jury). Students will recommend ways to prevent deforestation.
Evaluate: Acting like the scales of justice to 'weigh up' the evidence to make and justify a decision. Students will work in groups and act as judge-jury to assess and conclude the extent of destruction in Malaysia and globally. Determine and propose steps to prevent deforestation.
Students create a brochure on a personal action plan as a proposal to curb deforestation. Brochure will be uploaded on class blog.
Design: Acting like an inventor, experiencing 'light bulb' moments to generate new products, ideas or ways of doing things. Creatively design a brochure with graphics and recommendation on measures to curb deforestation.

The writing lessons in Table 2 were taught for one month based on the topic 'Environment' and students were given the essay title 'Deforestation'. The lessons (Table 1) were taught in the sequence of Blooms' levels of task 1 (Remember), task 2 (Understand), task 3 (Apply), task 4 (Analyse), task 5 (Evaluate) and task 6 (Design). In the first lesson, the teacher highlighted the TSF to the students and Blooms' six levels of cognitive domains, the use of appropriate verbs, sentence starters and the ways to employ the appropriate thinking tools. At the end of task 6, focus group interviews were conducted among 48 students who volunteered from the three intact ESL classes, with the aim of determining the extent to which HOT skills affect ESL students' learning of writing and their perceptions of learning writing using HOT skills. There were 2 focus groups interviews that were conducted for each class: Group A and Group B from class 1; Group $\mathrm{C}$ and $\mathrm{D}$ from class 2 and Group $\mathrm{E}$ and $\mathrm{F}$ from class 3. In analysing student responses in the focus group sessions, pseudonyms were used to reflect actual student views.

\section{Results}

\subsection{Students' perceptions of Bloom's taxonomy level 1 (Remember)}

In analysing student perceptions on this cognitive level, they were asked to talk about their experience, acting like an internet database to recall information. Kevin from Group A stated that "the KWHL helped me to remember the characteristics of descriptive writing". Six other students from Groups C, E and F concured with Kevin. Majority of the students were "excited" to pose each other with "WH" questions after researching for more information from the internet. Tan, from Group C, stated that:

My friends and I were excited. We felt so different. The normal writing lessons did not get us to this. By making 'Wh' questions, my friends and I were amazed at our excitement cos writing lessons were usually boring and frustrating actually". 
Students conveyed their experience, acting like an expert in understanding the reasons behind deforestation and explicating the extent to which deforestation has impcated on Malaysia's environment. Sheila, Mei Wan and Wong from Group F stated that the 'Wh' questions asked by the teacher had made them think "very deeply" about deforestation and Amirul from Group D said:

"I got further information from friends all over by chatting using facebook. Was proud of myself when I managed to get much more information compared to my friends. Some of my friends followed me in this way of getting information". Alice added: "I must say that $\mathrm{i}$ followed Amirul. This is the first time I used Facebook for classroom homweork".

Most students stated that they realised that the TSF helped them to be "aware of what was expected" from them in the lessons. They "felt that they performed better". A total of $80 \%$ of students were of the opinion the cause-effect map was helpful in understanding the ways in which deforestation has impacted Malaysia's environment.

\subsection{Students' perceptions of Bloom's taxonomy level 3 (Apply)}

Most students had collectively voiced out that they enjoyed themselves dramatising the cause and effect of deforestation. Alicia from Group B stated, "I am shy but wasn't during the role-play. It was awesome asking each other questions, writing the scripts and simply knowing so much ideas after interviewing people about deforestation". Many other students from the other two classes felt the same way as Alicia and the role-play was captured as video clips and uploaded on the class blog. When students were asked about their experience writing the descriptive essay, there were quite a number of responses that basically highlighted on students usually having a 'mental block' during writing but after experiencing the TSF lessons, students had "no problem and phobia" about writing essays.

\subsection{Students' perceptions of Bloom's taxonomy level 4 (Analyse)}

Almost all the students conveyed their "enthusiasm" acting like a magnifying glass to investigate relevant factors in relation to global deforestation. Siti, from Group A, said "My friends and I managed to get loads of information from our friends all over the world through Facebook chatting. We realised that deforestation is worst in other countries". Many students communicated similar opinions as Siti. The Fishbone diagram was a tool that "fascinated" students and they enjoyed the experience of applying their information to related writing activities in the classroom.

\subsection{Students' perceptions of Bloom's taxonomy level 5(Evaluate)}

From the six focus group sessions, it was clear that majority of students stated that they gained "confidence" in having the opportunity to assess and conclude on the extent of destruction that deforestation has caused in Malaysia and globally. The students who considered themselves "shy", stated that they felt "grand" at being able to assume the role of judge-jury. Most students also communicated that they were able to critically evaluate situations, discuss and recommend ways to control deforestation. Yusof from Group B stated "I am not usually confident of my evaluation ability but not any more though. I have realised my ablity to evaluate well". Audrey concurred with him and said "Oh yes ! I feel the same too and am proud of myself for doing a good job. I was amazed at myself for being able to assess ways to prevent deforestation and conclude the extent of destruction in Malaysia and globally". Similar responses were stated by the majority of students in the three classes.

\subsection{Students' perceptions of Bloom's taxonomy level 6 (Design)}

All students in the focus group sessions communicated to the researchers that they felt like an "inventor" designing the brochure containing information pertaining to an action plan which proposes to curb deforestation. Julian from Group C said, "I felt cool and creative designing the brochure especially the graphics. My friend edited it and other friends suggested colours and ideas for designing it. We worked so well together and never got this chance before". Several other students from Groups A, B and D shared similiar viewpoints and said that they imagined themselves being "future inventors".

\subsection{Students' perceptions of TSF}

The information gathered from students in the six focus group interview sessions can be summarised as follows:

- Students experienced tasks in all the six levels of Bloom's taxonomy that connected to their lives outside the classroom and that challenged them to think critically, produce creative written communication, engage in productive conversation and meaningfully engage with diverse groups of students.

- Students perceived the questions posed by the teacher as opportunities to think, to assist them in solving a problem, a process or a big idea. Teacher's construction of the following open-ended questions helped students to use HOT skills more effectively: "What do you think it means? What else could it mean?" "How do you know that?" "So what?" "What do you mean by that?" "Who disagrees and why?" "How is that connected?"

- Students developed their writing skills in writing an intoduction, body paragraphs and conclusion.

- Students were engaged and motivated in the learning process involving all the six cognitive domains of Bloom's taxonomy.

\section{Discussion \& Conclusion}


The findings from the focus group interviews indicate that students perceived their roles in the writing classroom as follows: they felt engaged in active learning, they experienced learner autonomy, they developed their writing, researching and personal skills as well. The HOT lessons promoted students' involvement and discussions in the classroom in which students believed that their ideas matter in the classroom. The HOT lessons tapped into students' prior knowledge by providing context-rich language resources and this concurs with Cummins, (1994) and Dong's, (2004) findings that language teachers play an important role to promote HOT skills aligned to language skills.

The students in this case study felt that HOT skills are nurtured by giving them a platform to compare, question, discuss, validate and reflect on their own and others' ideas. Research findings advocate that students from diverse ethnic and socio-economic environments in elementary and secondary stages of schooling should be given the platform to develop their HOT skills in real classroom teachings (Newman, Bryk \& Nagaoka, 2001). In this study, students' ability to question their peers and likewise, answer their teacher's questions, provided a new dimension in their thinking and this in turn helped to develop their writing skills. The TSF fostered HOT skills among students when they learned to use the critical and creative thinking tools in a practical way and engaged in co-operative learning.

The findings of the TSF concur with the claims made by Lewis and Smith (1993) that teachers need to delegate more time to instruction dealing with high-quality thinking as this helps students to develop HOT skills. When students learn HOT skills in relation to the TSF, creative and innovative ideas are generated accordingly; thus the learning outcomes can be achieved effectively.

The findings of this study suggest that HOT writing lessons facilitate students' writing ability and interest and should be explicitly infused in the teaching and learning of writing activities in ESL writing classrooms. The TSF which was used as a conceptual framework of this study confirms the extensive effect of HOT skills in promoting students learning outcomes in writing where it has the potential to enhance students' minds, leading to the production of a variety of alternatives, ideas, actions, solutions and design. To some extent, the findings of this study confirm the significant value of HOT skills in generating ideas so students have the potential in acquiring creative and critical thinking. While the findings of this case study cannot be generalised to all ESL classrooms in Malaysia, there is a possibility that the use of the TSF can be viewed as a viable option in the teaching of writing among other secondary school students, especially in regards to examining the potential of this framework in other ESL contexts.

\section{References}

Ames, C. (1992). Classrooms: Goals, structures, and student motivation. Journal of Educational Psychology, 84, 261271.

Cohen, L., Manion, L. \& Morrison, K. (2011). Research Methods in Education. London: Routledge.

Cummins,J. (1994). Knowledge, power, and identity in teaching English as a second language. In F. Genesee (Ed.), Educating second language children (pp. 33-38). New York: Cambridge University Press.

Curriculum Development Center. (1989). Integrated curriculum for secondary schools. Kuala Lumpur, Malaysia: Ministry of Education.

Dong, Y. R. (2004). Teaching language and content to linguistically and culturally diverse students: Principles, ideas, and materials- Greenwich. CT: Information Age Publishing.

Frangenheim, E. (2006). Thinking Skills Framework. [Online] Retrieved: 15 January, 2014. Available: http://www.itcpublications.com.

Hillocks, G. Jr. (1986). Research on Written Composition. Urbana, IL:ERIC Clearing House on Reading and Communication Skills. University of Chicago: NCRE Publications.

Kaplan, A., Middleton, M. J., Urdan, T., \& Midgley, C. (2002). Achievement goals and goal structures. In C. Midgley (Ed.), Goals, goal structure and patterns of adaptive learning (pp. 21-53). Mahwah, NJ: Erlbaum.

Lewis, A. \& Smith, D. (1993). Defining higher order thinking. Theory Into Practice, 32, 131-137.

Morshidi, S., Pandian, A., Muniandy, B., Fazal M., Harshita A., Hazita A., Muhammad K., \& Ratna R.A.R. (2008). The university curriculum and the employment of graduates. In Zuraidah Mohd Don (Ed.), Enhancing the quality of higher education through research: Shaping future policy (pp.939). Kuala Lumpur: Ministry of Higher Education Malaysia, (MoHE).

National Research Council, Committee on Research in Mathematics, Science, and Technology Education. "Education and Learning to Think.” Report published 1987. United States of America: National Academy Press.

Parmjit Singh, Roslind, T., \& Mohamad Adlan Ramly (2014). Fit or Unfit? Perspectives of Employers and University Instructors of Graduates' Generic Skills. Procedia - Social and Behavioral Sciences, 123(3), 315 - 324.

Newman, F. M., Bryk, A. S., \& Nagaoka, J. K. (2001). Authentic intellectual work and standardized tests: Conflict or coexistence? Consortium on Chicago School Research. Madison, WI: Wisconsin Center for Education Research.

Rosenshine, B. \& Meister, C. (1992). The Use of Scaffolds for Teaching Higher-Level Cognitive Strategies. Educational Leadership, 49 (7), 26-33.

Yee M. H., Jailani Md Yunos, Widad Othman, Razali Hassan, Tee T. K. \& Mimi Mohaffyza Mohamad (2012). The needs analysis of learning higher order thinking skills for generating ideas. Procedia - Social and Behavioral Sciences, $59(10), 197-203$.

Yin, R. K. (1984). Case study research: Design and methods. Newbury Park, CA: Sage. 